\title{
Knowledge-based fuzzy system for diagnosis and control of an integrated biological wastewater treatment process
}

\author{
O.C. Pires, C. Palma, J.C. Costa, I. Moita, M.M. Alves and E.C. Ferreira \\ Centro de Engenharia Biológica, Universidade do Minho, 4710-057 Braga, Portugal \\ (E-mail: olgapires@deb.uminho.pt)
}

\begin{abstract}
A supervisory expert system based on fuzzy logic rules was developed for diagnosis and control of a laboratory- scale plant comprising anaerobic digestion and anoxic/aerobic modules for combined high rate biological $\mathrm{N}$ and $\mathrm{C}$ removal. The design and implementation of a computational environment in LabVIEW for data acquisition, plant operation and distributed equipment control is described. A step increase in ammonia concentration from 20 to $60 \mathrm{mg} \mathrm{N} / \mathrm{L}$ was applied during a trial period of $73 \mathrm{~h}$. Recycle flow rate from the aerobic to the anoxic module and bypass flow rate from the influent directly to the anoxic reactor were the output variables of the fuzzy system. They were automatically changed (from 34 to 111 $\mathrm{L} /$ day and from 8 to $13 \mathrm{~L} /$ day, respectively), when new plant conditions were recognised by the expert system. Denitrification efficiency higher than $85 \%$ was achieved $30 \mathrm{~h}$ after the disturbance and $15 \mathrm{~h}$ after the system response at an HRT as low as $1.5 \mathrm{~h}$. Nitrification efficiency gradually increased from 12 to $50 \%$ at an HRT of $3 \mathrm{~h}$. The system proved to react properly in order to set adequate operating conditions that led to timely and efficient recovery of $\mathrm{N}$ and $\mathrm{C}$ removal rates.

Keywords Activated sludge; anaerobic digestion; distributed supervision; expert system; fuzzy logic based system; nutrient removal
\end{abstract}

\section{Introduction}

Conventional control methods are adequate when good analytical mathematical models are available to support their development and operation. This situation is uncommon in real processes. Particularly, the real-time control of wastewater treatment plants (WWTP) is a difficult but essential task, due to the lack of accurate dynamical models describing the process and reliable on-line instrumentation (Olsson and Newell, 1999). However, WWTP can be operated by staff with knowledge about the process, though in practice, this know-how is essentially qualitative, empirical and incomplete. The operation of a WWTP represents therefore a knowledge intensive task. In this regard, a system capable of giving all the possible information about the state of the process must be available in order to establish the basis of a diagnosis system integrating all the possible knowledge. This requirement is an important step to facilitate successful control decisions (Patry and Chapman, 1989). Applications of knowledge-based systems to activated sludge processes are being widely studied (Chapman et al., 1989; Barnett et al., 1992; Ozgur and Stenstrom, 1994). Most are off-line knowledge-based expert systems (KBES) that are mainly diagnostic and advisory tools to help process operators. Some KBES have been designed with the main purpose of on-line supervision, with real-time supervisor control usually being absent.

Intelligent control, merging the tools of artificial intelligence into the control loop, whether in the direct digital control or in the supervision tasks, is a very promising technique. Fuzzy systems (allowing to process qualitative knowledge and to design 
qualitative-reasoning based controllers) and neural networks (allowing building parametric nonlinear models and controllers in a constructive way) are tools that already proved their capabilities (Müller et al., 1997; Du et al., 1999).

In biological wastewater treatments processes, efficient diagnosis and control systems are becoming more and more important due to the complexity of the bioprocesses involved. It is difficult to take into account the numerous factors that can influence the specific bacterial growth rate and its metabolic activity. Several types of disturbances may greatly affect the operating conditions of a process, even in normal conditions. Data acquisition systems allow an overview of the state giving information about the operation. Monitoring comprises both hardware-based (sensors, etc.) and software-based (data-mining - from data to knowledge; software sensors allowing the estimation of nonmeasured variables) sensing. Particularly, for high rate combined $\mathrm{N}$ and $\mathrm{C}$ removal systems, monitoring is a very important feature in order to assure its control. The development of reliable on-line instrumentation is necessary due to the complexity of these integrated biological systems. Control and diagnosis of the biological systems are required to ensure the stable operation of a WWTP.

Baeza et al. $(1999,2000)$ reported the implementation of an expert supervisory system applied to a pilot WWTP comprising anaerobic and nitrification/denitrification steps to remove nitrogen. A fuzzy control strategy was applied by Meyer and Pöpel (2003) for the control of aeration in wastewater treatment plants with pre-denitrification. The implementation of expert systems based on fuzzy logic rules are described elsewhere (Carrasco et al., 2002; Puñal et al., 2002a,b). Recently, attention to the expert supervision and control of anaerobic digestion processes has been reported (Flores et al., 2000; Genovesi et al., 1999; Polit et al., 2002).

In this work, a supervisory expert system based on fuzzy logic rules was developed for the diagnosis and the control of a high rate laboratory-scale wastewater treatment plant used for organic matter and nitrogen removal. The fuzzy rules for diagnosis and control were integrated in the fuzzy logic rule based system, using quantitative and qualitative information.

\section{Methods}

Plant description

The laboratory-scale plant is based on a two-stage anaerobic/anoxic granular sludge bed reactors with $8 \mathrm{~L}$ and $8.5 \mathrm{~L}$, respectively, working at $37^{\circ} \mathrm{C}$, followed by a $14 \mathrm{~L}$ nitrifying activated sludge tank, and a $2.5 \mathrm{~L}$ settler. A synthetic effluent, with a COD concentration of $2500 \mathrm{mg} / \mathrm{L}$ and a nitrogen concentration of $20 \mathrm{mg} \mathrm{N}-\mathrm{NH}_{4}^{+} / \mathrm{L}$, was fed to an equalization tank, and then was pumped to the anaerobic module. When necessary, a bypass from the equalisation tank was directly applied to the anoxic stage to assure efficient denitrification. To test the fuzzy logic expert system, a step increase on nitrogen concentration from 20 to $60 \mathrm{mg} \mathrm{N}-\mathrm{NH}_{4}^{+} / \mathrm{L}$ was imposed during a period of $73 \mathrm{~h}$. The nitrified effluent from the activated sludge tank was recirculated to the anoxic module. The remaining COD from anaerobic stage was used as the electron donor to the nitrogen removal step in the anoxic module. The seed sludge for the anaerobic and the anoxic modules was anaerobic granular sludge collected at a UASB reactor treating brewery wastewater. A schematic layout of the process plant is shown in Figure 1. Bioreactors were equipped with two biogas flowmeters (Ritter Apparatebau, GmbH, Bochum, Germany), a TFK 325 thermometer (WTW, Weilheim, Germany), two SensoLyt pH electrodes connected to a 296 R/RS monitor (WTW), an ORP Electrolyt 9816 probe (WTW), a ViSolid 700 IQ total suspended solids infrared 


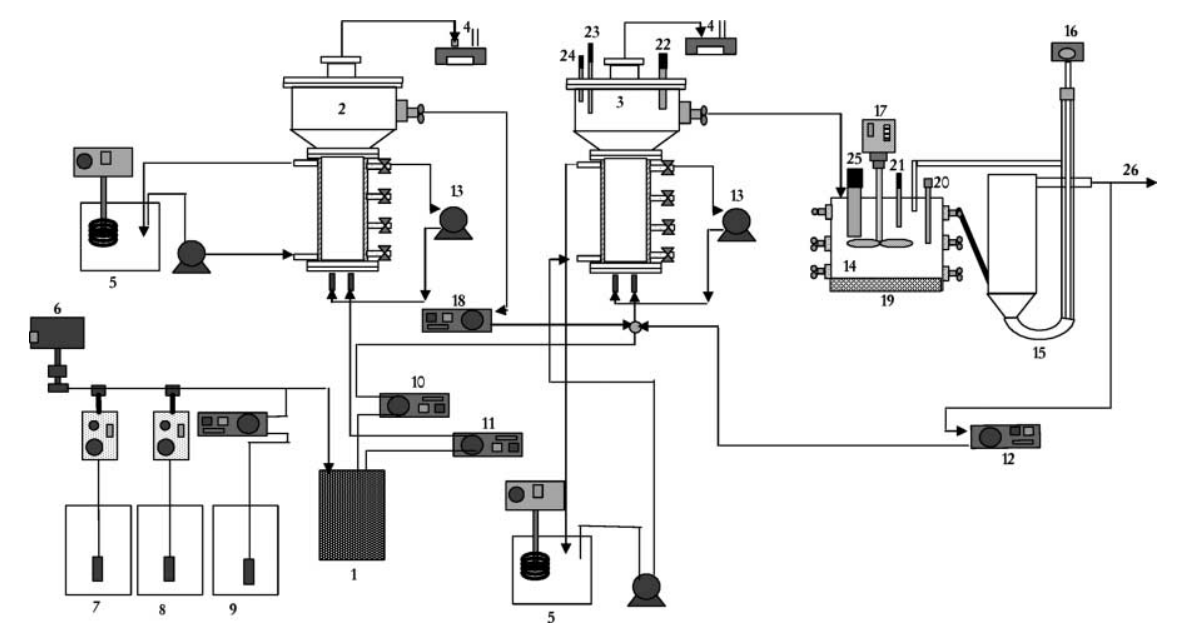

Figure 1 Schematic layout of the plant: (1) equalisation tank; (2) anaerobic reactor; (3) anoxic reactor; (4) gas flowmeters; (5) heat exchanger; (6) water regulation valve; (7) N source storage tank; (8) C source storage tank; (9) nutrient storage tank; (10) bypass pump; (11) feeding pump; (12) external recycle pump; (13) internal recycle pumps; (14) aerated tank; (15) settler; (16) air pump; (17) stirrer; (18) anaerobic reactor to anoxic reactor pump; (19) aeration system; (20) dissolved oxygen probe; (21) pH probe; (22) ORP probe; (23) pH probe; (24) Pt-100 thermometer; (25) TSS probe; (26) outlet

probe (WTW). A sequential injection determination apparatus (Paralab, Porto, Portugal) was used for nitrite, nitrate and ammonium on-line determination. Acetate was measured off-line by HPLC (Jasco, Japan) and converted to COD concentration values.

\section{On-line sequential injection analysis of nitrogen forms}

A sequential injection analysis (SIA) system was developed to determine nitrite, nitrate and ammonia concentrations in the reactors. Nitrite was determined through formation of a reddish purple azo dye produced at $\mathrm{pH} 2.0-2.5$ by coupling diazotized sulfanilamide with N-(1-naphthyl)-ethylinediamine dihydrochloride (APHA et al., 1989). The reddish purple dye was detected spectrophotometrically at $540 \mathrm{~nm}$. The cadmium reduction method was used to determine nitrates. Nitrates were reduced to nitrite by using a copperised-cadmium column. The method was based on the quantification of both ions using two samples from the same point of the plant. First nitrites, then nitrates were analysed. Nitrites and nitrates were detected from a range of 2 to $100 \mathrm{mgN}-\mathrm{NO}_{2}^{-}$and 5 to $100 \mathrm{mgN}-\mathrm{NO}_{3}^{-}$, respectively. $50 \mu \mathrm{l}$ of sample were analysed every $2 \mathrm{~h}$ in triplicate.

Ammonium determination was based on the Nessler method (APHA et al., 1989). $30 \mu \mathrm{l}$ of sample was collected every $2 \mathrm{~h}$ and ammonium concentration determined by detection of a yellow compound at $470 \mathrm{~nm}$.

An automated sampling system was installed to obtain a continuous flow of sample free of biomass. It was composed of a peristaltic pump used for each sample point in the aspiration and the recycle circuits, an A-SEP tangential microfilter unit (Applikon, The Netherlands), and a set of three-way pinch solenoids electrovalves (S-307, Sirai, Italy) to select the sampling circuit.

\section{Software/hardware}

Three distributed network personal computers (PC) are used to monitor and control the plant operation: a supervisory computer responsible for data acquisition, data storage, equipment control, and hosting a web server; a second computer that controls the 
sequential injection analysis (SIA) system; a third local PC is used to command peristaltic pumps. The LabVIEW (National Instruments, USA) graphical development environment was used for the distributed software tasks of signal acquisition and processing, measurement analysis, data presentation, network and data socket communication, and internet publication. Data are acquired periodically and recorded to Excel format files. The supervisory computer is equipped with a PCI 6024-E board (National Instruments, USA). Two PCL-718 boards (Advantech, Taiwan) are installed in the pumps control PC. The Fuzzy Logic toolbox for MATLAB (The Mathworks, Inc., USA) was used to embed the fuzzy logic system in LabVIEW.

\section{Communications}

A TCP/IP communication protocol is established between both supervisory and pump control computers to remotely control the peristaltic pumps. The SIA system, although controlled from the SIA PC, can be also controlled from the supervisory PC, using the data socket protocol communication. Digital output signals are using to open/close the electrovalves of the SIA automated sampling system. The peak values are acquired and ionic concentrations determined and stored on the supervisory PC, also by the data socket protocol communication. The plant is equipped with in-line sensors (dissolved oxygen, temperature, $\mathrm{pH}$, ORP and total suspended solids) interfaced to monitors interconnected in a BUS system. The supervisory computer acquires data from the monitors using the digital RS-485 protocol. Total suspended solids monitor provided analogue signals in the range of 4-20mA. These signals were converted to $0-5$ volts, which are acquired in the differential input mode through the PCI 6024-E board. Feeding pumps are controlled by a squared wave signal ranging from 0 to 5 volts issued from the PCI board. Biogas flow rates data are acquired using a digital counter of pulses generated by the gas flow meters.

\section{Remote internet access}

LabVIEW front panels of the supervisory program are published on the internet for remote access from a common web browser. Anyone with the proper permissions can access and control the laboratory-scale plant using the free LabVIEW run-time engine installed on the client computer. Visual feedback is also provided from embedded live images captured from webcams.

\section{The fuzzy rules based expert system}

A supervisory expert system was built using the rule based structure IF 'facts' THEN 'conclusions (state or action)'. A rule derives operating knowledge from given facts, and is generated from human knowledge. A fact is a description of the relationship between an input variable and its output variable. The rule based structure is made using the Fuzzy Logic toolbox for MATLAB. The rules are distinguished in five levels (very high, high, normal, low and very low), in order to be used by the diagnosis and control system. Fuzzy C Means and Fuzzy Rule are used to build the diagnosis and the control systems respectively. The Fuzzy Rule Base algorithm embedded in MATLAB Fuzzy Logic toolbox has the following steps: the scalar inputs are transformed into memberships of fuzzy sets by fuzzifying functions; this information is given to the inference engine; then membership values are transformed into the required scalar output variables by a defuzzification step.

The ranges of values corresponding to different levels of each variable are presented in Tables 1 and 2. The main objective of the control system is to ensure low concentrations of nitrate, nitrite and COD in the plant effluent, actuating in the output 
Table 1 Labels of the input variables used for the control system: $\mathrm{N}$, ammonium concentration in the plant influent; $\mathrm{C} / \mathrm{N}$, the $\mathrm{COD} / \mathrm{N}$ ratio in the influent of the anoxic reactor

\begin{tabular}{|c|c|c|c|c|c|}
\hline & V.L & $\mathbf{L}$ & $\mathbf{N}$ & H & V.H \\
\hline$\left[\mathrm{N}-\mathrm{NH}_{4}^{+}\right]_{\text {in }}(\mathrm{mg} / \mathrm{L})$ & $0<\mathrm{N}<10$ & $10<\mathrm{N}<30$ & $30<\mathrm{N}<50$ & $50<\mathrm{N}<80$ & $80<\mathrm{N}<120$ \\
\hline COD/N & $0<\mathrm{C} / \mathrm{N}<2$ & $2<\mathrm{C} / \mathrm{N}<4$ & $4<\mathrm{C} / \mathrm{N}<6$ & $6<\mathrm{C} / \mathrm{N}<9$ & $9<\mathrm{C} / \mathrm{N}<15$ \\
\hline
\end{tabular}

Table 2 Labels of the output variables used for the control system: R recycle flow rate (L/day); B bypass flow rate (L/day)

\begin{tabular}{|c|c|c|c|c|c|}
\hline & COD/N (V.L) & COD/N (L) & COD/N (N) & COD/N (H) & COD/N (V.H) \\
\hline \multirow[t]{2}{*}[\mathrm{N}-\mathrm{NH}_{4}^{+}]{$_{\text {in }}(\mathrm{V} . \mathrm{L})$} & $0<\mathrm{B}<1$ & $0<\mathrm{B}<1$ & $0<\mathrm{B}<1$ & $0<\mathrm{B}<1$ & $0<\mathrm{B}<1$ \\
\hline & $0<\mathrm{R}<1$ & $0<\mathrm{R}<1$ & $0<\mathrm{R}<1$ & $0<\mathrm{R}<1$ & $0<\mathrm{R}<1$ \\
\hline \multirow{2}{*}[\mathrm{N}-\mathrm{NH}_{4}^{+}]{$_{\text {in }}(\mathrm{L})$} & $1<\mathrm{B}<3$ & $1<\mathrm{B}<3$ & $0<\mathrm{B}<1$ & $0<\mathrm{B}<1$ & $0<\mathrm{B}<1$ \\
\hline & $3<\mathrm{R}<67$ & $3<\mathrm{R}<67$ & $3<\mathrm{R}<67$ & $3<\mathrm{R}<67$ & $3<\mathrm{R}<67$ \\
\hline \multirow[t]{2}{*}[\mathrm{N}-\mathrm{NH}_{4}^{+}]{$_{\text {in }}(\mathrm{N})$} & $3<\mathrm{B}<5$ & $3<\mathrm{B}<5$ & $0<\mathrm{B}<1$ & $0<\mathrm{B}<1$ & $0<\mathrm{B}<1$ \\
\hline & $67<\mathrm{R}<135$ & $67<\mathrm{R}<135$ & $67<\mathrm{R}<135$ & $67<\mathrm{R}<135$ & $67<\mathrm{R}<135$ \\
\hline \multirow[t]{2}{*}[\mathrm{N}-\mathrm{NH}_{4}^{+}]{$_{\text {in }}(\mathrm{H})$} & $5<B<8$ & $5<B<8$ & $3<\mathrm{B}<5$ & $0<\mathrm{B}<1$ & $0<B<1$ \\
\hline & $135<\mathrm{R}<236$ & $135<\mathrm{R}<236$ & $135<\mathrm{R}<236$ & $135<\mathrm{R}<236$ & $135<\mathrm{R}<236$ \\
\hline \multirow[t]{2}{*}[\mathrm{N}-\mathrm{NH}_{4}^{+}]{$_{\text {in }}(\mathrm{V} . \mathrm{H})$} & $8<\mathrm{B}<10$ & $8<\mathrm{B}<10$ & $3<\mathrm{B}<5$ & $0<\mathrm{B}<1$ & $0<\mathrm{B}<1$ \\
\hline & $236<\mathrm{R}<370$ & $236<\mathrm{R}<370$ & $236<\mathrm{R}<370$ & $236<\mathrm{R}<370$ & $236<\mathrm{R}<370$ \\
\hline
\end{tabular}

variables of the fuzzy control system, which are the external recycle $(\mathrm{R})$ and the bypass (B) flow rates. The $\mathrm{COD} / \mathrm{N}$ ratio at the influent of the anoxic reactor and the ammonium concentration in the influent of the plant are the two input variables considered in the control system. The membership-functions for the input variables are illustrated in Figure 2. Linear membership-functions are used to describe the input variables (Figure 3).

\section{Results and discussion}

The supervisory system was tested on the laboratory-scale biological wastewater treatment process described above. The wastewater is made by mixing two concentrated streams of carbon (acetate) and nitrogen (ammonium chloride) diluted with tap water. Different COD and nitrogen concentrations and flow rates are automatically assigned and scheduled by the supervisory computer. This artefact enables simulation of real influent situations of organic and hydraulic shocks.

Figure 4 presents results concerning each reactor operation, when a step increase in nitrogen concentration from 20 to $60 \mathrm{mg} \mathrm{N} / \mathrm{L}$ (keeping constant the influent COD) was applied at time 0 for $73 \mathrm{~h}$. During this period the process was monitored every $2 \mathrm{~h}$. Owing to the off-line nature of some analytical techniques, the supervisory system received information with a delay. However after $15 \mathrm{~h}$, the output of the fuzzy system was able to set the proper flow conditions. The fuzzy system automatically increased the recycle flow rate from 34 to $111 \mathrm{~L} /$ day and the bypass flow rate from 8 to $13 \mathrm{~L} /$ day (Figure $4 \mathrm{~b}$ ), in order to remove the surplus nitrate and to maintain the COD/N ratio necessary to remove all nitrogen.

In the anaerobic module, a slight decrease in the COD removal efficiency was observed, from 96 to $85 \%$. The HRT ranged from $8.9 \mathrm{~h}$ to $10.7 \mathrm{~h}$ (Figure $4 \mathrm{a}$ ). The fluctuations in the HRT of this module were consequences of the bypass flow rate adjustments needed to provide enough COD for efficient denitrification in the anoxic 

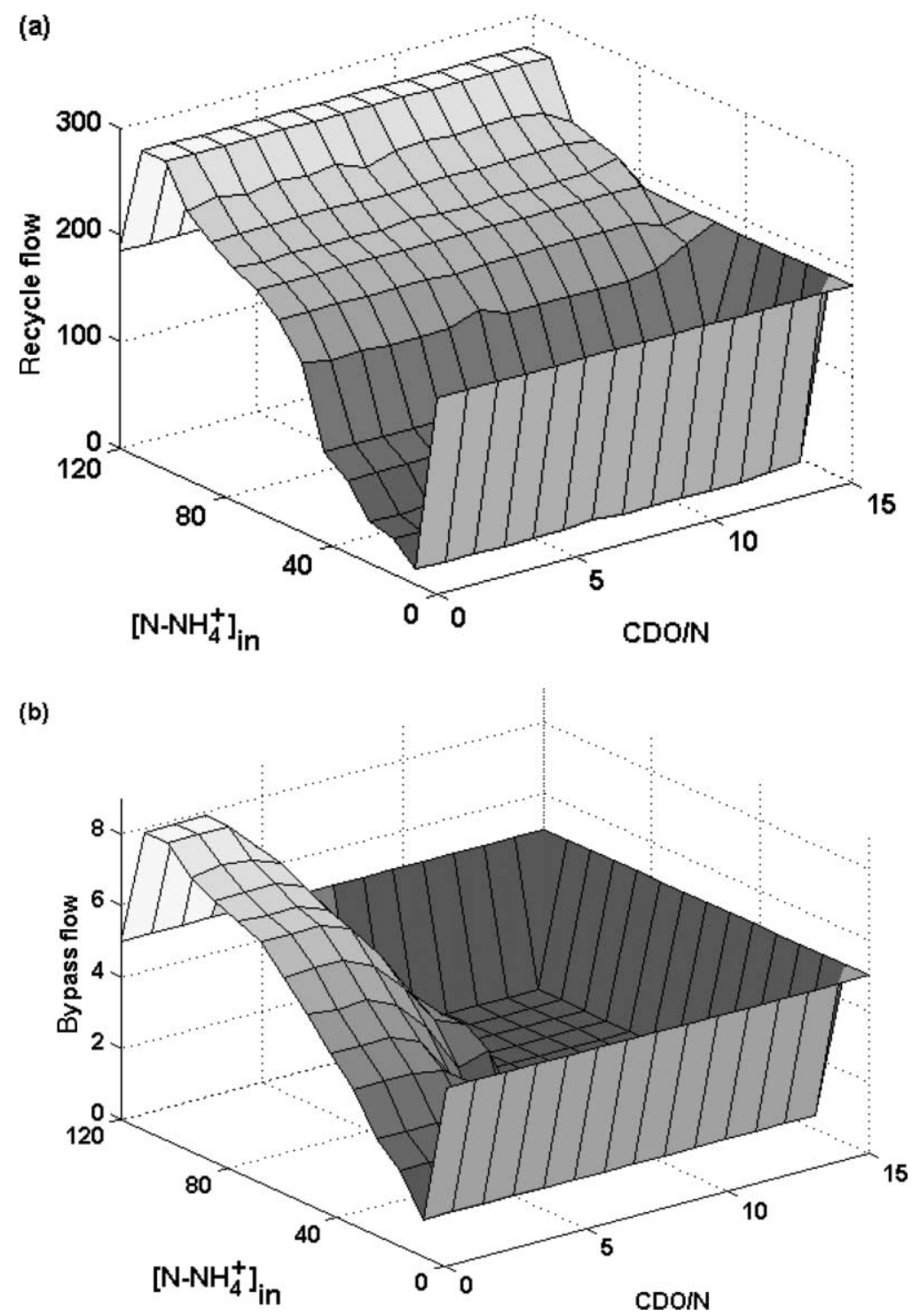

Figure 2 Surface plot of the fuzzy logic control system: (a) output recycle flow (R) and (b) bypass flow (B) versus $\mathrm{COD} / \mathrm{N}$ ratio and $\mathrm{N}-\mathrm{NH}_{4}^{+}$concentration in the effluent

module. The bypass flow rate is therefore directly dependent on the COD removal efficiency of the anaerobic reactor. The decrease in the bypass flow rate after the first adjustment (Figure 4b), is due to the decrease in the COD removal efficiency in the anaerobic module. The anoxic reactor achieved a maximum of $89 \% \mathrm{~N}^{-\mathrm{NO}_{\mathrm{x}}^{-}}$ (nitrate and nitrite) conversion to $\mathrm{N}_{2}$ gas, at an HRT as low as $1.4 \mathrm{~h}$ (Figure 4c). The $\mathrm{C} / \mathrm{N}$ ratio was maintained higher than the theoretical value of 4.7 during the assay and the excess COD that was not used for denitrification was efficiently converted to methane (not shown). The specific methanogenic acetoclastic activity of the granular sludge in this module was $71 \%$ of the inoculum value. The decrease on the hydraulic retention time in the nitrification tank to a value of $3 \mathrm{~h}$ did not impair the rise in the ammonia removal efficiency from 12 to $50 \%$ during the trial period (Figure 4d). 
(a)

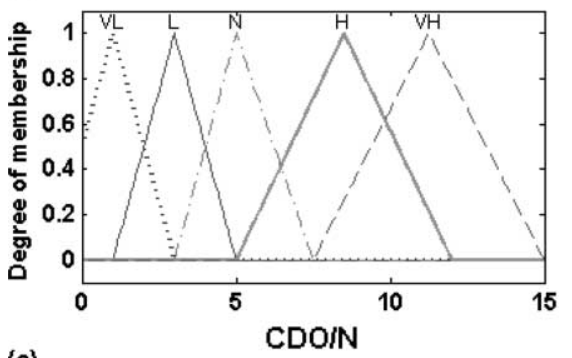

(c)

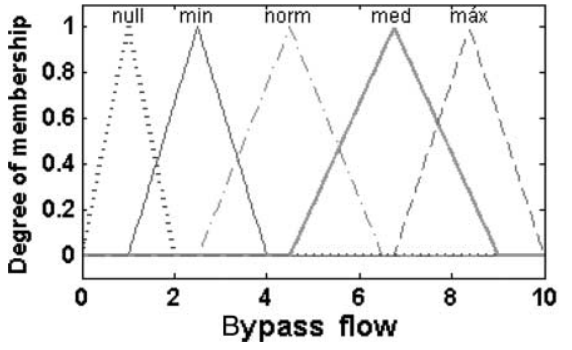

(b)

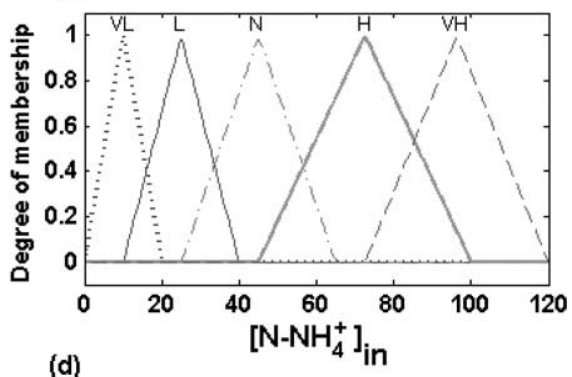

(d)

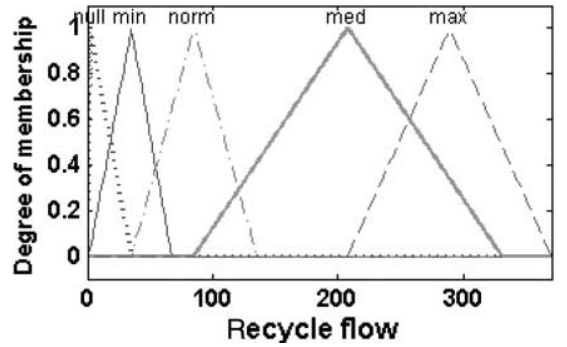

Figure 3 Membership-functions of the fuzzy logic control system. Input variables: (a) COD/N ratio and (b) $\mathrm{N}-\mathrm{NH}_{4}^{+}$concentration in the effluent. Output variables: (c) bypass flow and (d) recycle flow

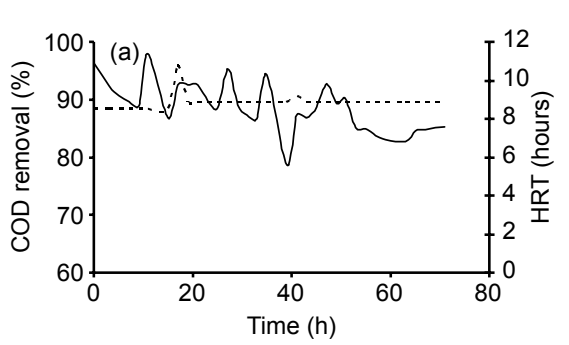

_ COD removal, . . . . HRT

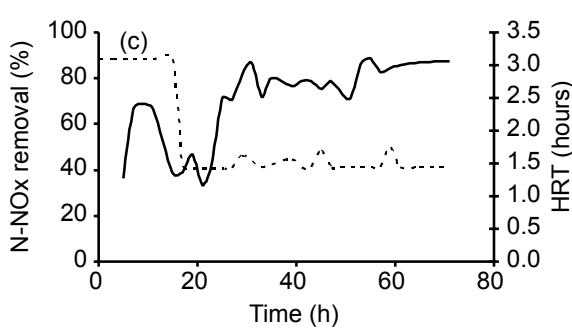

-N-NOx removal, . . . - HRT

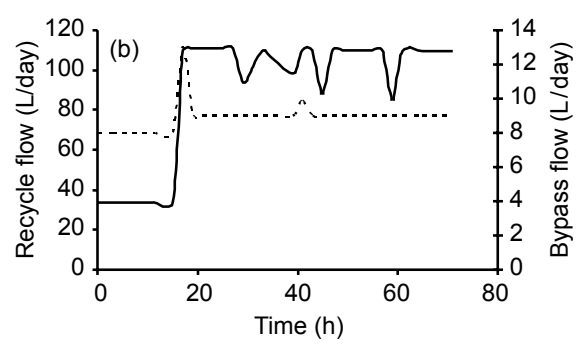

_recycle flow, . . . - bypass flow

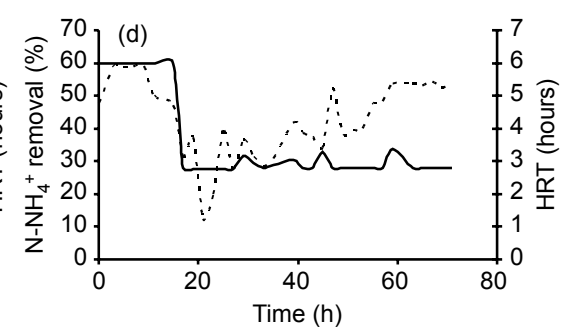

.... - N-NH+ removal, _

Figure 4 Time course of main variables during the nitrogen overload: (a) anaerobic reactor; (b) anoxic reactor; (c) anoxic reactor; and (d) nitrification tank

\section{Conclusions}

A KBES rule based fuzzy logic was developed and applied to a laboratory-scale plant comprising anaerobic/anoxic/aerobic modules for combined high rate biological $\mathrm{N}$ and $\mathrm{C}$ removal. A step increase in ammonia concentration from 20 to $60 \mathrm{mg}$ N/L was applied during a trial period of $73 \mathrm{~h}$. Recycle flow rate from the aerobic to the anoxic module and bypass flow rate from the influent directly to the anoxic reactor were the output of the fuzzy system that were automatically changed (from 34 to $111 \mathrm{~L} /$ day and from 8 to 
$13 \mathrm{~L} /$ day, respectively), when new plant conditions were recognised by the expert system. Denitrification efficiency higher than $85 \%$ was achieved $30 \mathrm{~h}$ after the disturbance and $15 \mathrm{~h}$ after the system response at an HRT as low as $1.5 \mathrm{~h}$. Nitrification efficiency gradually increased from 12 to $50 \%$ at an HRT of $3 \mathrm{~h}$. The system proved to properly react in order to set adequate operating conditions that timely led to recover efficient $\mathrm{N}$ and $\mathrm{C}$ removal rates.

\section{Acknowledgements}

The authors thank Fundação para a Ciência e a Tecnologia for financial support to O. Pires and J.C. Costa through the doctoral research grants BD/1299/2000 and BD/13317/2003, respectively. The helpful comments of Dr Russell Patterson were also appreciated.

\section{References}

APHA, AWWA, WPCF (1989). Standard Methods for the Examination of Water and Wastewater, 17th edn, Washington D.C.

Baeza, J.A., Ferreira, E.C. and Lafuente, J. (2000). Knowledge-based supervision and control of wastewater treatment plant: a real-time implementation. Wat. Sci. Tech., 41(12), 129-137.

Baeza, J.A., Gabriel, D. and Lafuente, J. (1999). An expert supervisory system for a pilot WWTP. Environ. Modelling \& Software, 14, 383-390.

Barnett, M.W., Patry, G.G. and Hiraoka, M. (1992). Knowledge-based (expert) systems for the activated sludge process. Andrews, J.F. (ed.), Dynamics and Control of the Activated Sludge Process, Technomic Publ. Co., Lancaster, pp. 231-243.

Carrasco, E.F., Rodríguez, J., Puñal, A., Roca, E.C. and Lema, J.M. (2002). Rule-based diagnosis and supervision of a pilot-scale wastewater treatment plant using fuzzy logic techniques. Exp. Syst. Appl., 22, $11-20$.

Chapman, D., Patry, G.G. and Hill, R. (1989). Dynamic modeling and expert systems in wastewater engineering: trends, problems, needs. Patry, G.G. and Chapman, D. (eds), Dynamic Modeling and Expert Systems in Wastewater Engineering, ch. 11, Lewis Publ., Chelsea, pp. 345-370.

Du, Y.G., Tyagi, R.D. and Bhamidimarri, R. (1999). Use of fuzzy neural-net model for rule generation of activated sludge process. Proc. Biochem., 35, 77-83.

Flores, J., Arcay, B. and Arias, J. (2000). An intelligent system for distributed control of an anaerobic wastewater treatment process. Artif. Intell., 13, 485-494.

Genovesi, A., Harmand, J. and Steyer, J.-P. (1999). A fuzzy logic based diagnosis system for the online supervision of an anaerobic digester pilot-plant. Biochem. Eng. J., 3, 171-183.

Meyer, U. and Pöpel, H.J. (2003). Fuzzy-control for improved nitrogen removal and energy saving in WWWT-plants with pre-denitrification. Wat. Sci. Tech., 47(11), 69-76.

Müller, A., Marsilli-Libelli, S., Aivasidis, A., Lloyd, T., Kroner, S. and Wandrey, C. (1997). Fuzzy control of disturbances in a wastewater treatment process. Wat. Res., 31(12), 3157-3167.

Olsson, B. and Newell, B. (1999). Wastewater Treatment Systems - Modelling, Diagnosis and Control, IWA publishing, London.

Ozgur, N.H. and Stenstrom, M.K. (1994). KBES for Process control of nitrification in activated sludge process. J. Environ. Eng., 120(1), 87-107.

Patry, G.G. and Chapman, D. (1989). Dynamic Modeling and Expert Systems in Wastewater Engineering, Lewis Publishers, Chelsea.

Polit, M., Estaben, M. and Labat, P. (2002). A fuzzy model for an anaerobic digester, comparison with experimental results. Artif. Intell., 15, 385-390.

Puñal, A., Rodríguez, J., Carrasco, E.F., Roca, E. and Lema, J.M. (2002a). An expert system for monitoring and diagnosis of anaerobic wastewater treatment plants. Wat. Res., 36, 2656-2666.

Puñal, A., Rodríguez, J., Carrasco, E.F., Roca, E. and Lema, J.M. (2002b). Expert system for the online diagnosis of anaerobic wastewater treatment plants. Wat. Sci. Tech., 45(10), 195-200. 